\title{
Benign and malignant mixed tumours of the lung
}

\author{
P. W. DAVIS, J. C. BRIGGS, R. M. E. SEAL, and \\ F. K. STOR RIN G \\ Llandough and Sully Hospitals, Cardiff, and Frenchay Hospital, Bristol
}

Ten patients are presented with tumours complying with the criteria established by the World Health Organization for 'mixed tumours of the lung'.

A slowly growing intrabronchial neoplasm indistinguishable from a pleomorphic adenoma (mixed salivary tumour) and a peripheral circumscribed tumour with most of the features of a chondromatous hamartoma were considered benign.

Of eight malignant neoplasms two were regarded as 'pulmonary blastomas', one with a benign epithelial tubular component and the other with cytological evidence of malignancy in the tubular epithelium; in both, the stroma was 'embryonic' and pleomorphic. Three tumours were considered carcinosarcomas with a mainly epidermoid epithelial component and a pleomorphic spindle-cell connective tissue component. In the remaining three tumours the malignant epithelial component showed mixed, viz., epidermoid, tubular, and a variety of undifferentiated appearances, while the 'stroma' exhibited features seen in both blastomas and carcinosarcomas. These three neoplasms were considered 'transitional'.

The spectrum of appearances encountered constitutes, in our opinion, a serious objection to the thesis that peripheral pulmonary blastomas and carcinosarcomas are distinct entities with a separate histogenesis. Exceptions were found to 'blastomas' being peripheral and carcinosarcomas being central growths. A case is made for reclassification of the benign and malignant neoplasms included in the WHO group IX 'mixed tumours of the lung'.

The most authoritative classification of lung tumours is that by the World Health Organization, namely the International Histological Classification of Tumours: No. 1. Histological Typing of Lung Tumours (Kreyberg, 1967). Many tumours which may be regarded as mixed are included. A mixed epithelial malignancy, the combination of epidermoid and adenocarcinoma (V), and the mucoepidermoid tumours $\left(\mathrm{VII}_{2}\right)$ are classified separately and are clearly defined. Teratomas which occur in the lung rarely are not listed separately.

There remains an ill-defined group of tumours (IX), headed 'mixed' tumours and carcinosarcomas. The general description of this group states that tumours with a structure resembling mixed salivary tumours are tentatively grouped with other tumours in which elements resembling epithelium are mixed with cells resembling those of connective tissue. Three subdivisions are listed in this group, viz.:

\section{1. 'mixed' tumours}

2. carcinosarcomas of embryonal type ('blastomas')

3. other carcinosarcomas.
It is not apparent which benign tumours are included in the group under subdivision 1. Clearly, from the general description, which mentions tumours with a structure resembling mixed salivary tumours, the rare pleomorphic adenoma of the bronchus is included. However, it is not clear whether the benign common 'chondromatous hamartoma' warrants inclusion and whether a cytologically 'benign' form of blastoma is intended to fall into this category.

A review of the literature also reveals some confusion regarding terminology and interrelationships of the benign tumours of the group. Willis (1962), for example, refers to the "chondromatous hamartoma' as a benign mixed tumour of the bronchus, while Spencer (1968) prefers the term 'local pulmonary hamartoma' and describes two varieties, both peripheral in location, the first being the common variety with cartilage as a constant component (chondromatous hamartoma), and the rarer second variety without cartilage, consisting of tubular structures within undifferentiated mesenchymal tissue. The latter he considers to be closely related to pulmonary blastomas. Spencer (1968), accepting Waddell's (1949) theory of the development of the lung, which 
postulates that major bronchi develop from the entodermal bud and peripheral airways and air sacs from mesoderm, designates the common cartilage-containing tumour as 'central', and the rarer non-cartilagenous neoplasm with an embryonic stroma as 'peripheral'. These terms are clearly used in a histogenetic sense.

The term 'pulmonary blastoma' was used by Spencer (1961) when presenting three examples of a neoplasm consisting of tubular epithelial-lined structures in a polymorphic and spindle-cell stroma. In this report he included a fourth case previously reported by Barnard (1952) as an 'embryoma' of the lung. Two of these tumours were malignant in that either blood or lymphatic metastasis occurred. The WHO description for the comparable tumour, "carcinosarcoma of embryonal type' (blastoma), is 'masses of polygonal or stellate cells in a very loose stroma that resembles embryonic mesenchyme and in which irregular acinar tissue is frequently embedded and sometimes masses of squamous epithelium. Muscle fibres are sometimes present'.

Carcinosarcomas of the lung, although rare, have been reported in the literature for many years. Since the first well-documented case reports by Saltykow (1914) and Frank (1915) over 30 cases of carcinosarcoma of the lung have been published. This figure includes a series of cases derived from a review by Stackhouse, Harrison, and Ellis (1969). Opinion is divided concerning the connective tissue origin of the sarcoma-like component in these tumours. Saphir and Vass (1938) and Willis (1962), for example, consider that in the majority the sarcoma-like areas are derived from the epithelial component. Among others, Drury and Stirland (1959) make a strong case for the acceptance of a true sarcomatous component in these rare tumours.

The WHO description of this type of carcinosarcoma is that of poorly differentiated cells having characteristics of sarcoma of soft tissue together with well-differentiated epithelium of the types occurring in carcinoma of the bronchus. A subtype mentioned is a polypoid intrabronchial tumour with mucus-producing cells in several layers lining large acini with a stroma of proliferating spindle-shaped cells.

Bergmann, Ackerman, and Kemler (1951), Taylor and Rae (1952), and Drury and Stirland (1959) have suggested that carcinosarcomas have a more favourable prognosis than carcinoma of the lung. A similar claim has been made for pulmonary blastomas by Spencer (1961), Souza, Peasley, and Takaro (1965), and Barson, Jones, and Lodge (1968).
We describe 10 patients with lung tumours fulfilling the criteria of histopathological type IX (Kreyberg, 1967). These tumours illustrate the inadequacy of the present criteria: they show a wide spectrum of histological patterns with a considerable overlap between the individual tumours. Modifications to the classification are suggested.

\section{CLINICAL MATERIAL}

Our material has been drawn from two regional thoracic centres (Sully/Llandough Hospitals, Cardiff, and Frenchay Hospital, Bristol), covering a period of six years, with the exception of our first case, a rare mixed salivary tumour (pleomorphic adenoma) of the bronchus, which had been resected 24 years ago. The other benign tumour presented (case 2) was one of 36 peripheral circumscribed hamartomas containing cartilage and was one of a few consisting entirely of embryonic stroma and tubular epithelium at its growing margin. It was selected to illustrate this feature. The malignant tumours represent all the neoplasms of this type recognized in both centres during this period.

\section{METHODS}

Appropriate blocks were taken from the material after formol saline inflation of the lungs, and the stains used were phosphotungstic acid haematoxylin (PTAH), periodic acid Schiff (PAS), alcian blue (Lison's), and reticulin stain (Gordon and Sweet) in addition to haematoxylin and eosin ( $\mathrm{H}$ and $\mathrm{E})$ and van Gieson's stain.

\section{CASE REPORTS}

CASE 1 M.S., a woman, aged 52 years, was admitted in 1948 with respiratory symptoms following an attack of pneumonia four years previously. A chest radiograph showed a homogeneous irregular opacity in the right upper lobe. At bronchoscopy a white jelly-like growth was seen protruding from the right upper lobe bronchus. A bronchial biopsy specimen at the time was reported as being indistinguishable from a 'mixed salivary tumour'. At operation a right pneumonectomy was performed. The patient died in the postoperative period and no necropsy was performed.

Surgical specimen The macroscopic appearances were those of a right pneumonectomy specimen showing a white glistening mucoid tumour, approximately $45 \times 25 \times 25 \mathrm{~mm}$, in the upper lobe bronchus. The tumour grew distally to distend a segmental bronchus with marked associated bronchiectasis and chronic pneumonitis of the apical and posterior segments (Fig. 1).

Microscopic appearances The epithelial elements of the tumour were arranged in strands and occasional clumps were dispersed throughout a somewhat 


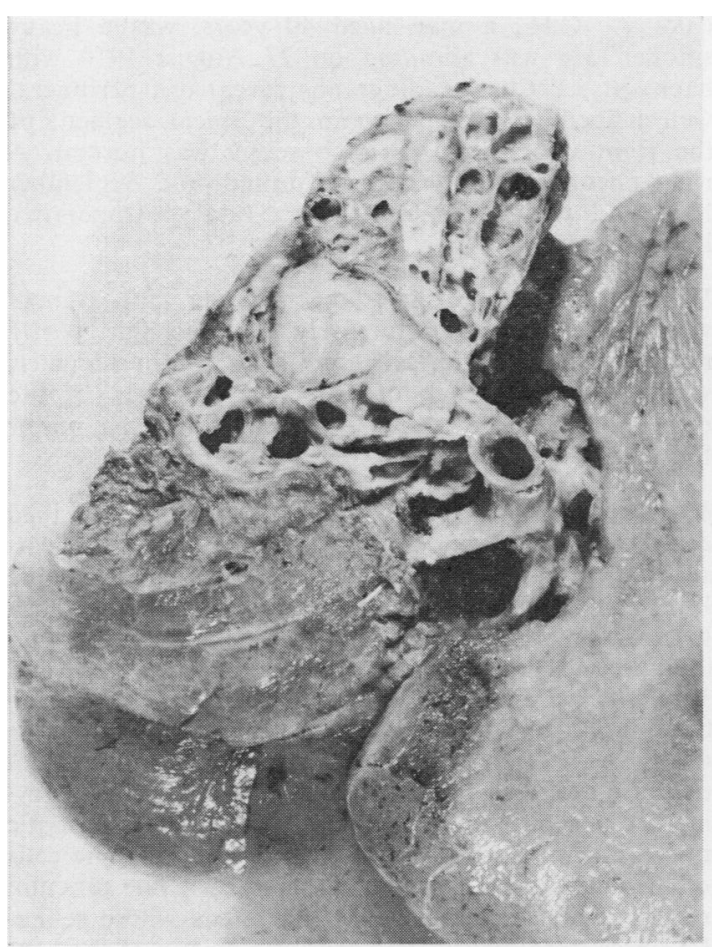

FIG. 1. Cut surface of right upper lobe to show tumour and parenchymal damage.

hyaline stroma. There was no differentiation into tubules or squamous epithelium. The cells, for the most part, were regular and no mitoses could be seen. The 'stromal' component of the tumour was basically structureless but there were areas of fibril formation. Alcian blue staining revealed the presence of large amounts of connective tissue mucin (Fig. 2).

Comment The overall features of this tumour are those of a pleomorphic adenoma arising almost certainly from the bronchial submucous glands.

CASE 2 I.T.B., a man aged 68 years, was admitted on 4 February 1971 with myocardial infarction. He gave a recent history of dyspepsia and haematemesis. He died on the day of admission. Necropsy confirmed myocardial infarction as the immediate cause of death; also found were a neoplasm of the stomach (adenocarcinoma) and a tumour in the left lung.

Surgical specimen The macroscopic appearances were those of a circumscribed glistening peripheral white, slightly lobulated tumour, $25 \mathrm{~mm}$ in diameter, in the left lower lobe.

Microscopic appearances This was a benign tumour with several components. The central area had the typical appearance of a chondromatous hamartoma, there being much true cartilage and vascular fatty connective tissue and a complex system of tubular epithelial structures lined by ciliated columnar epithelium around its growing margin. There were, however, a loose, ill-defined, slightly cellular stroma devoid of any cartilage, and epithelial spaces lined by simple low cuboidal epithelium (Fig. 3).

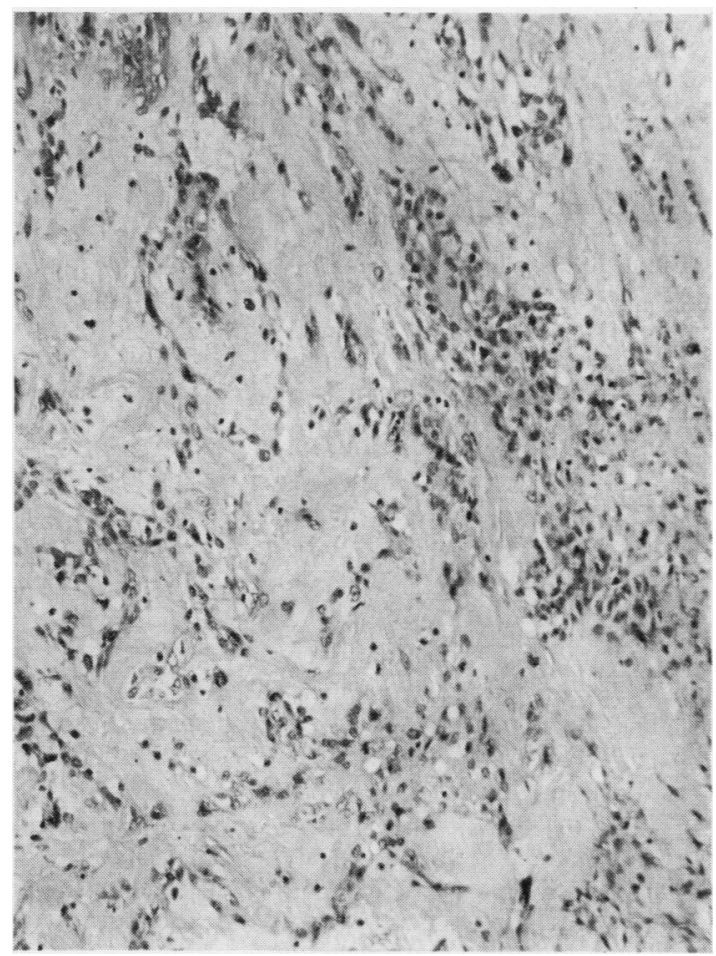

FIG. 2. A typical field showing a mucinous stroma with strands of epithelial cells. Alcian blue $\times 55$.

Comment The tumour is regarded basically as a chondromatous hamartoma but is included because the epithelial and stromal areas described above raise the question of the relationship of this neoplasm to non-cartilaginous local hamartomas and 'benign' pulmonary blastomas.

CASE 3 S.B., aged 58 years, was admitted on 18 October 1967 with a 10-week history of dyspnoea and productive cough. Chest radiographs revealed a partially collapsed and consolidated right upper lobe and at bronchoscopy a tumour occluded the right main bronchus, and was reported as a malignant neoplasm of unspecified type. A right pneumonectomy was performed on 8 November 1967. The patient had an uneventful postoperative period apart from a right empyema in June 1968. He died suddenly on 15 October 1968. There was no necropsy, death being attributed to coronary artery disease. 


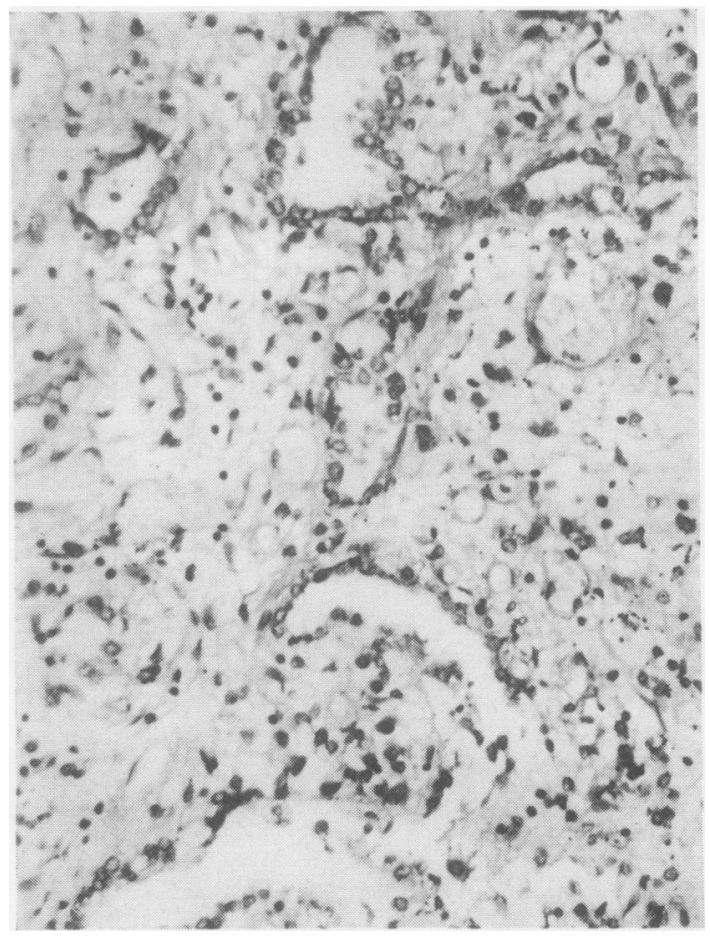

FIG. 3. Loose slightly cellular stroma containing tubular structures lined by simple low cuboidal epithelium. $H$. and $E$. $\times 55$.

Surgical specimen The macroscopic appearances were those of a nodular, yellow tumour, $50 \times 50 \times$ $40 \mathrm{~mm}$ in the posterior segment of the right upper lobe involving and protruding from the segmental bronchus into the lobar bronchus.

Microscopic appearances The tumour was encapsulated by collagen and composed of numerous epithelial islands in a 'stroma' which consisted of a mixture of spindle and round cells. The epithelial elements were somewhat variable: in some places they consisted of small dark, pleomorphic and hyperchromatic cells with little cytoplasm, but in the main the epithelium was multilayered, columnar, and pleomorphic with many mitoses; in other places there was a marked clear cell change (Fig. 4). The 'stromal' component of the tumour was cellular, with spindle cells and plump cells, the former often surrounding the epithelial islands, the latter being seen mainly in other areas. Mitosis was infrequent. The reticulin pattern was in the main fine and open (Fig. 4). The ground substance was slightly alcian-blue positive.

Comment The combination of a moderately cellular stroma without overt cytological evidence of malignancy, but with a malignant epithelial component, indicates that this tumour is to be regarded as a blastoma.
CASE 4 C.H., a man aged 40 years, was a heavy smoker. He was admitted on 27 August 1970 with haemoptysis. Chest radiographs revealed a peripheral well-defined round opacity in the apical segment of the right upper lobe. Bronchoscopy was normal. A right pneumonectomy was performed on 2 September 1970 and was complicated by a fatal postoperative haemorrhage.

Surgical specimen The macroscopic appearances were those of a large, intensely haemorrhagic, partly necrotic, almost spherical tumour, $70 \mathrm{~mm}$ in diameter, which occupied much of the apical segment of the right lower lobe without involvement of the major bronchi.

Microscopic appearances This was a circumscribed cellular mixed tumour. The epithelial elements showed tubular structures, some consisting of a single layer of non-ciliated columnar cells with dark, hyperchromatic nuclei (Fig. 5); in others, the epithelium was multilayered with frequent mitoses (Fig. 5). There were occasional 'clear cells'. PAS and alcian blue stains revealed only scanty epithelial mucin in the lumen of a few tubules. The 'stromal' component of the tumour was in most parts highly cellular, vary- $N$ ing from round to spindle cells with hyperchromatic nuclei and numerous mitotic figures (Fig. 5). The cells of this component were surrounded by a fine reticulin network, in contrast to epithelial areas where reticulin fibres were scanty. The cells and matrix of the connective tissue were PAS positive and faintly alcianblue positive.

An unusual feature was the presence of numerous extracellular, PAS positive circular 'globules', varying in size from 2 to $20 \mathrm{mU}$ in diameter. In a vascular and haemorrhagic area of the tumour the epithelial elements appeared to merge with the 'stroma'.

Comment The combination of a simple tubular $\underset{\times}{\vec{D}}$ epithelial structure and a 'primitive' stroma warrants $\bar{\sigma}$ the diagnosis of pulmonary blastoma. In this particular instance both components show large areas of cytological malignancy.

CASE 5 T.G., a 58-year-old coal miner, was a heavy 윽 smoker. He was admitted on 16 August 1968 with a $D$ six months' history of dyspnoea and weight loss. 을 Chest radiographs revealed an opacity in a partially collapsed right lower lobe, and at bronchoscopy a $\sigma$ tumour protruded beyond the right middle lobe $N$ bronchus. Biopsy material consisted of completely necrotic tumour tissue with a fine reticulin pattern. $\omega$ A middle and lower lobectomy was performed on 30 우 August 1968. At follow-up one year later there wase local recurrence in the thoracotomy scar and right $\frac{C}{\mathbb{D}}$ pleura. Metastases developed in the lumbar spine, ribs, $\stackrel{\mathscr{O}}{\rightarrow}$ and liver. The chest wall mass was biopsied. He died $\square$ 18 months after pneumonectomy and there was no $\overline{0}$ necropsy.

Surgical specimen The macroscopic appearances $\frac{\overrightarrow{\mathbb{D}}}{\Omega}$ were those of a white oval tumour, partly obstructing 


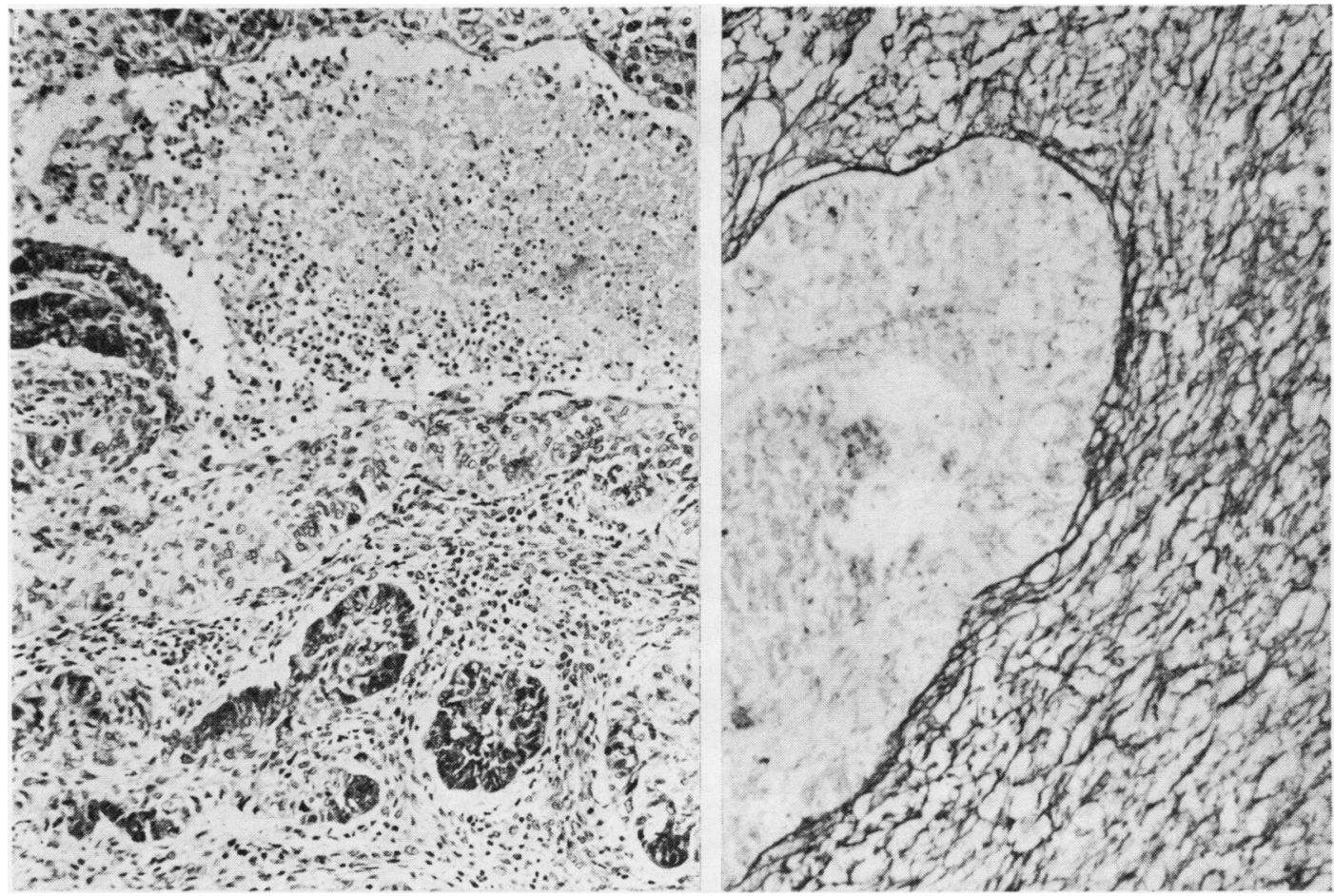

FIG. 4. (Left) The larger epithelial island, mainly clear cell, with sharply demarcated central necrosis. Smaller islands containing dark pleomorphic cells in a partly spindle-cell stroma. H. and E. $\times 30$. (Right) $A$ fine reticulin pattern in the connective tissue component surrounding an epithelial island with central necrosis. Reticulin stain $\times 55$.
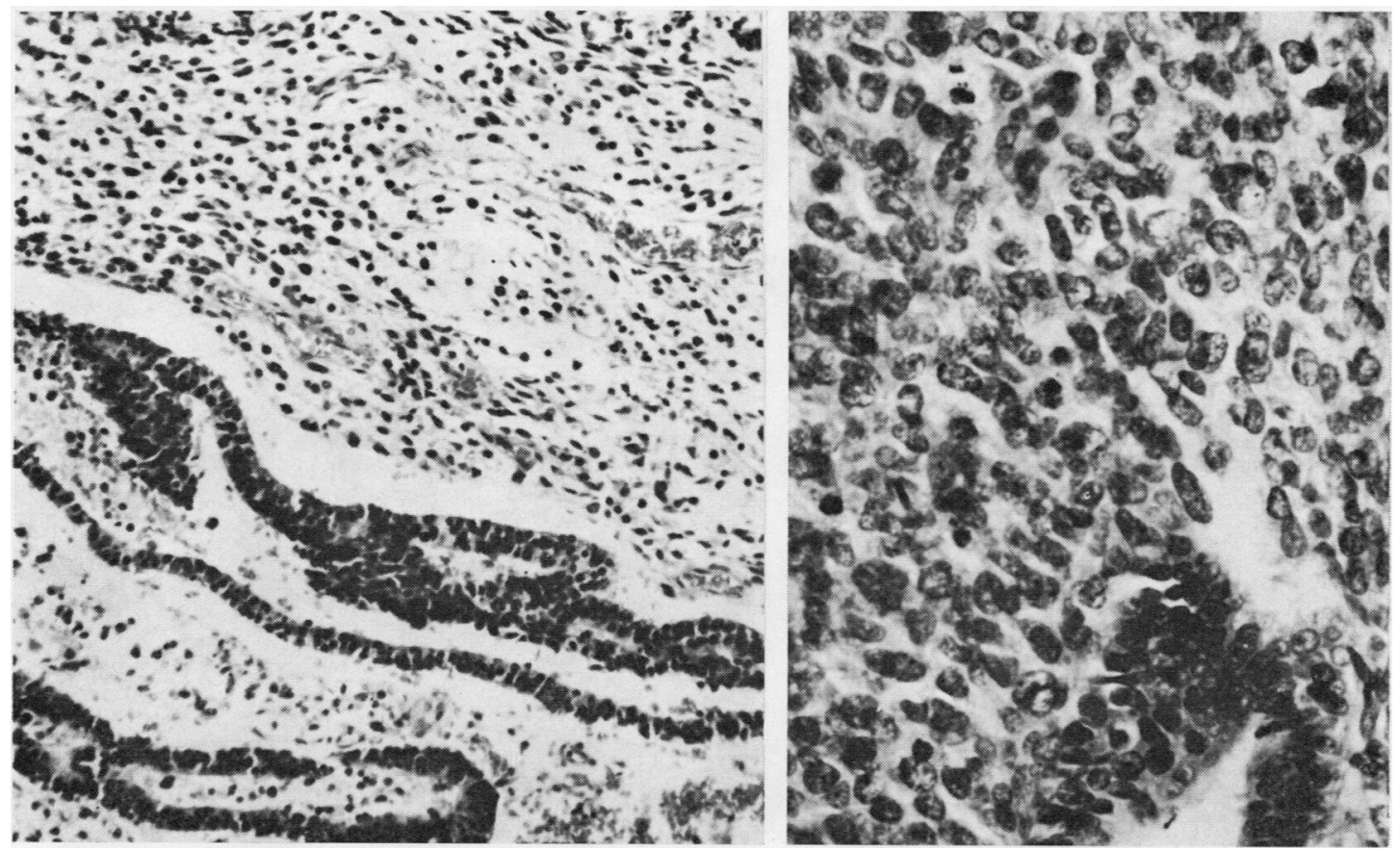

FIG. 5. (Left) Tubular epithelial structures in a slightly cellular stroma. $H$. and E. $\times 55$. (Right) Multilayered epithelial structures (bottom right) in a cellular stroma with frequent mitotic figures in both components of the tumour. H. and $E . \times 70$. 


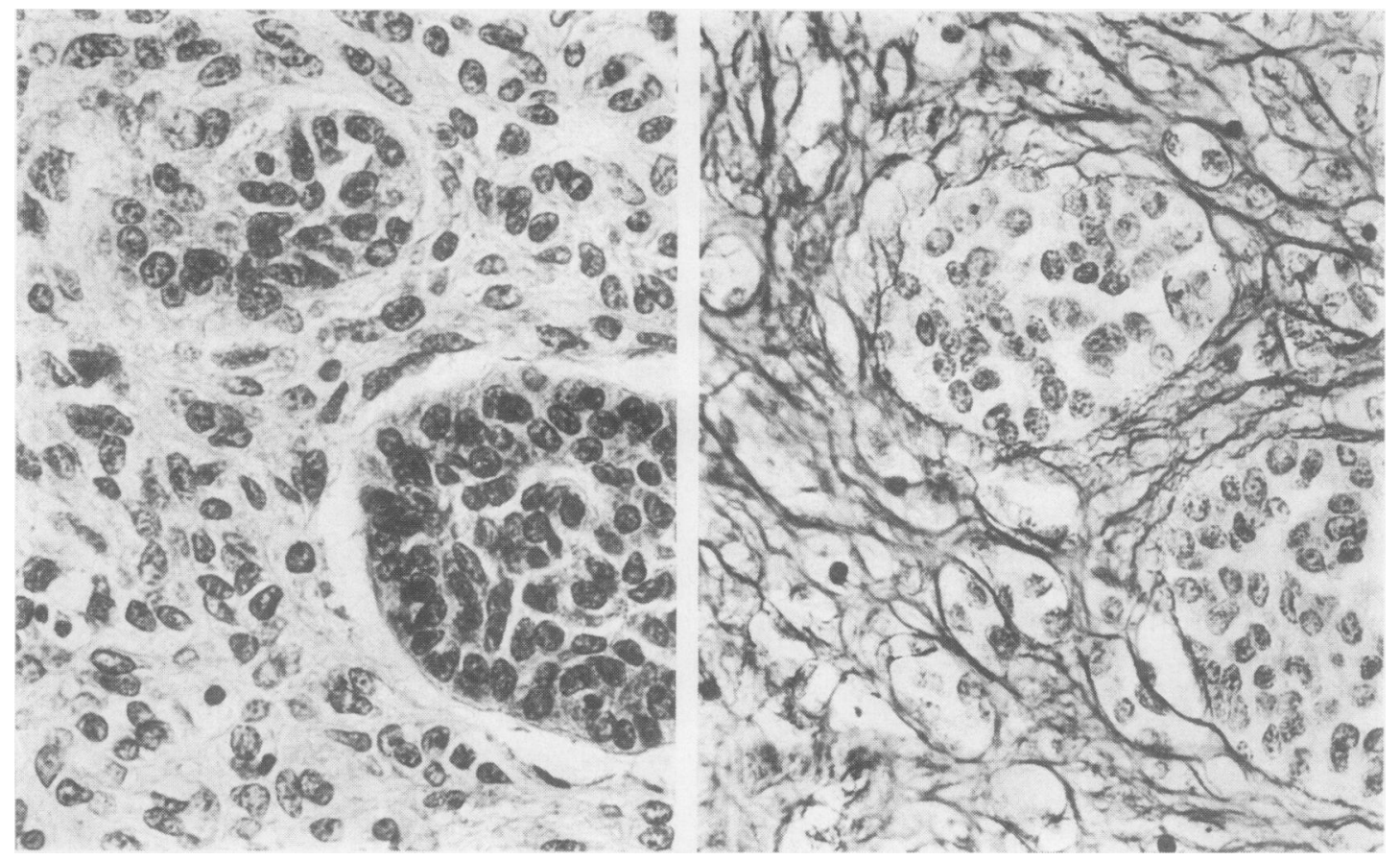

FIG. 6. (Left) Two islands of hyperchromatic, slightly pleomorphic epithelial cells surrounded by round and oval stroma cells with vesicular nuclei. There is a suggestion of epithelial streaming into the stroma. H. and E. $\times 70$. (Right) Step section showing a reticulin stromal pattern with epithelial islands devoid of reticulin fibres but some clumps of cells separate from the main islands. Reticulin stain $\times 70$.
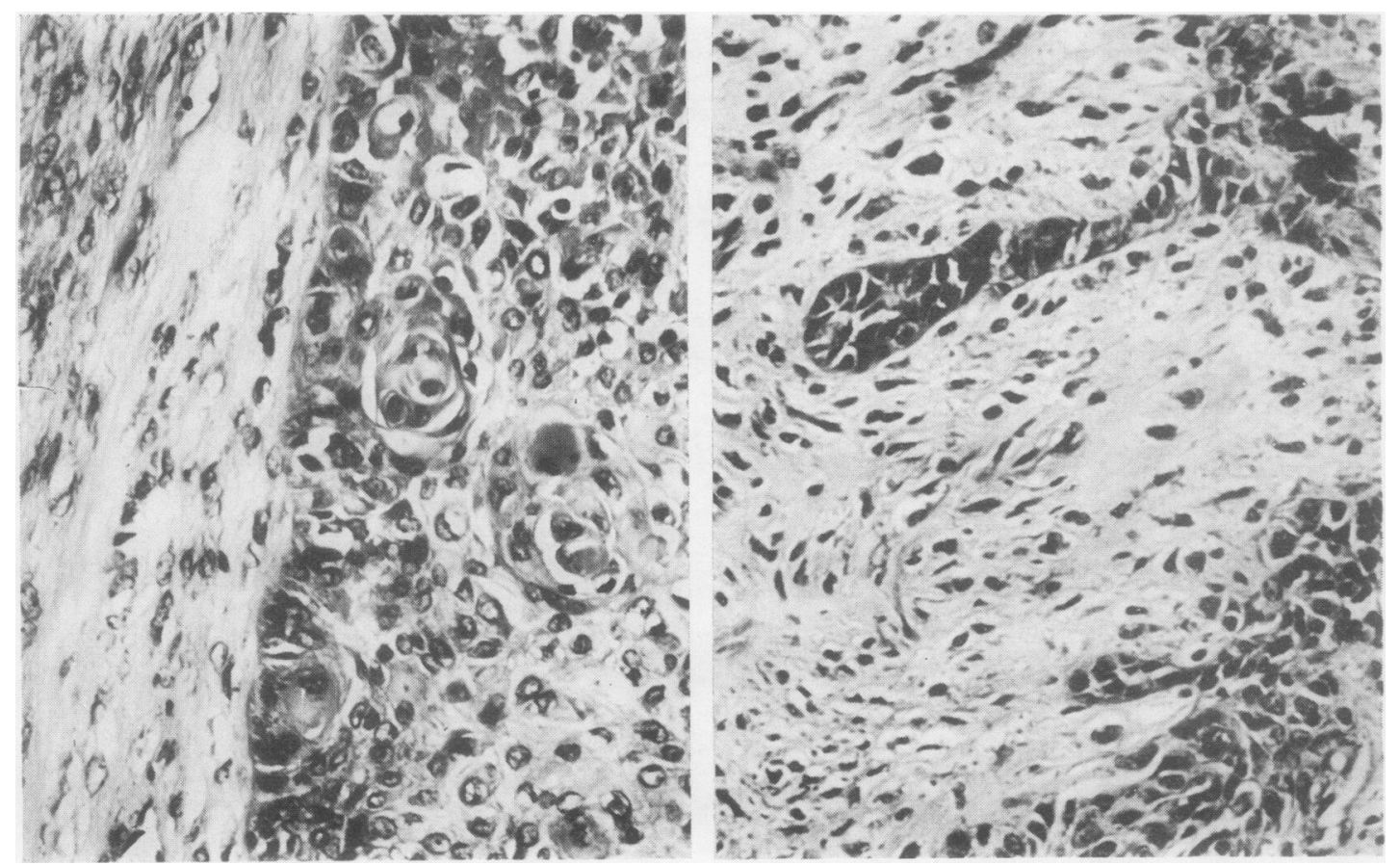

FIG. 7. (Left) Islands of epidermoid carcinoma with several foci of keratinization in a spindle-celled collagenous stroma. $H$. and E. $\times 70$. (Right $)$ Tubular epithelial structures in a hyalinized stroma. H. and E. $\times 70$. 
the lower lobe bronchus and involving the adjacent pulmonary parenchyma, producing a firm mass $50 \times$ $20 \times 20 \mathrm{~mm}$. There was distal obstructive pneumonitis.

Microscopic appearances The tumour was composed of epithelial and 'stromal' components with a wide variation within each. The epithelial elements near the surface of the intrabronchial portion of the tumour showed islands of small hyperchromatic, slightly pleomorphic epithelial cells (Fig. 6). In other parts of the tumour the islands of epithelium were overtly epidermoid with cell nests (Fig. 7). In yet other parts there were tubular epithelial structures in a less cellular hyalinized stroma, many fields being reminiscent of a mixed salivary tumour (Fig. 7). The 'stromal' component in the intrabronchial portion of the tumour consisted in places of loose 'embryonic' tissue. There were round and spindle cells with marked pleomorphism, and occasional elongated non-striated tumour giant cells. Mitoses were numerous. There were fine fibrillary structures in a lightly eosinophilic, PAS positive matrix. As in the bronchoscopic biopsy, the 'embryonic' stromal areas contained a uniform fine reticulin pattern: elsewhere the reticulin pattern was somewhat coarser, surrounding small groups of cells near the epithelial islands, suggesting the possibility of epithelial streaming into the stroma (Fig. 6).

Microscopic appearances of recurrence in scar This showed a pleomorphic, spindle-cell tumour with much collagen in some fasciculi, and occasional giant tumour cells as seen in the stroma of the original tumour. The appearances suggested a metastasis of the sarcomatous component.

Comment The simple forms of 'stroma' and epithelium seen in some places in this tumour are similar to those of a pulmonary blastoma. Elsewhere the stromal and epithelial differentiation is more suggestive of a carcinosarcoma. This tumour is considered to be a 'transitional' form between blastoma and carcinosarcoma.

CASE 6. W.T., a 65-year-old man, was a heavy smoker with a chronic productive cough. He was admitted on 22 February 1970 with a two-month history of haemoptysis. Chest radiographs revealed collapse consolidation of the left lower lobe. Further radiographs showed progressive atelectasis proceeding to total collapse of the left lung. At bronchoscopy the left main bronchus was found to be almost completely obstructed by a fungating neoplasm, a biopsy being reported as a malignant neoplasm, possibly a squamous carcinoma. On 29 March 1970 a left pneumonectomy was performed followed by artificial ventilation for respiratory failure. Subsequent death was due to hypoxic cerebral damage.

Surgical specimen The macroscopic appearances were those of a polypoid tumour, $30 \mathrm{~mm}$ in greatest diameter, growing from the upper lobe bronchus, occluding the main bronchus, and extending into the lumen of the anterior segmental bronchus of the upper lobe. The tumour was attached to the wall of the upper lobe bronchus but did not appear to infiltrate the lung tissue.

Microscopic appearances The tip of the polypoidal tumour was ulcerated and covered with an inflammatory and fibrinous exudate, and there was no invasion deep to bronchial cartilage. The main mass consisted of a mixture of epithelium and 'stroma'. A small piece of cartilage was present within the tumour near its basal edge. The epithelial element was present throughout and was mainly an epidermoid carcinoma. Occasional areas of more cuboidal epithelium were also present (Fig. 8). The 'stromal' component was spread throughout the entire tumour but was maximal at the tip. In all areas it consisted of a mixture of oval and spindle-shaped forms in varying proportions. It was rich in reticulin and virtually every cell was surrounded by a cloak of this substance. Mitoses were numerous. There was only one area suggestive of transition between the epithelial and the stromal elements (Fig. 8). In places the stroma was reminiscent of embryonic mesenchyme.

Comment The cuboidal component in the epithelial areas is reminiscent of the epithelial features of pulmonary blastomas, a diagnosis also suggested by the appearance of the stroma in places. The mainly epidermoid epithelial component, the spindle-cell stroma, and its intrabronchial location suggest a carcinosarcoma, and it is therefore considered a transitional form between blastoma and carcinosarcoma.

CASE 7 I.S., a woman aged 61 years, was admitted on 28 September 1966 with a history of recently increasing dyspnoea. Chest radiographs before admission were normal. Further radiographs following admission showed partial collapse of the left lower lobe progressing after some days to total collapse of the left lung. On bronchoscopy the left main bronchus was totally obstructed by tumour, which was reported to be a very poorly differentiated squamous-cell carcinoma. A left pneumonectomy was performed on 4 October 1966. During the operation the tumour became detached and occluded the right main bronchus, being removed via the left main bronchus. The patient was lost to follow-up after being well when last seen in January 1967.

Surgical specimen The macroscopic appearances were those of a piece of polypoid tissue, $25 \times 10 \times$ $10 \mathrm{~mm}$.

Microscopic appearances A mixed tumour with considerable variability of the epithelial elements which occurred as islands in a mainly spindle-cell 'stroma'. In the epithelial element many of the epithelial islands consisted of epidermoid carcinoma. Other epidermoid areas showed much clear cell change merging into central necrosis. In yet other epithelial islands there was transition from low columnar epithelium into clear cell, squamous, and, in some places, small cell carcinoma (Fig. 9). Mitotic figures were plentiful. The 'stromal' component, though mainly spindle-celled 

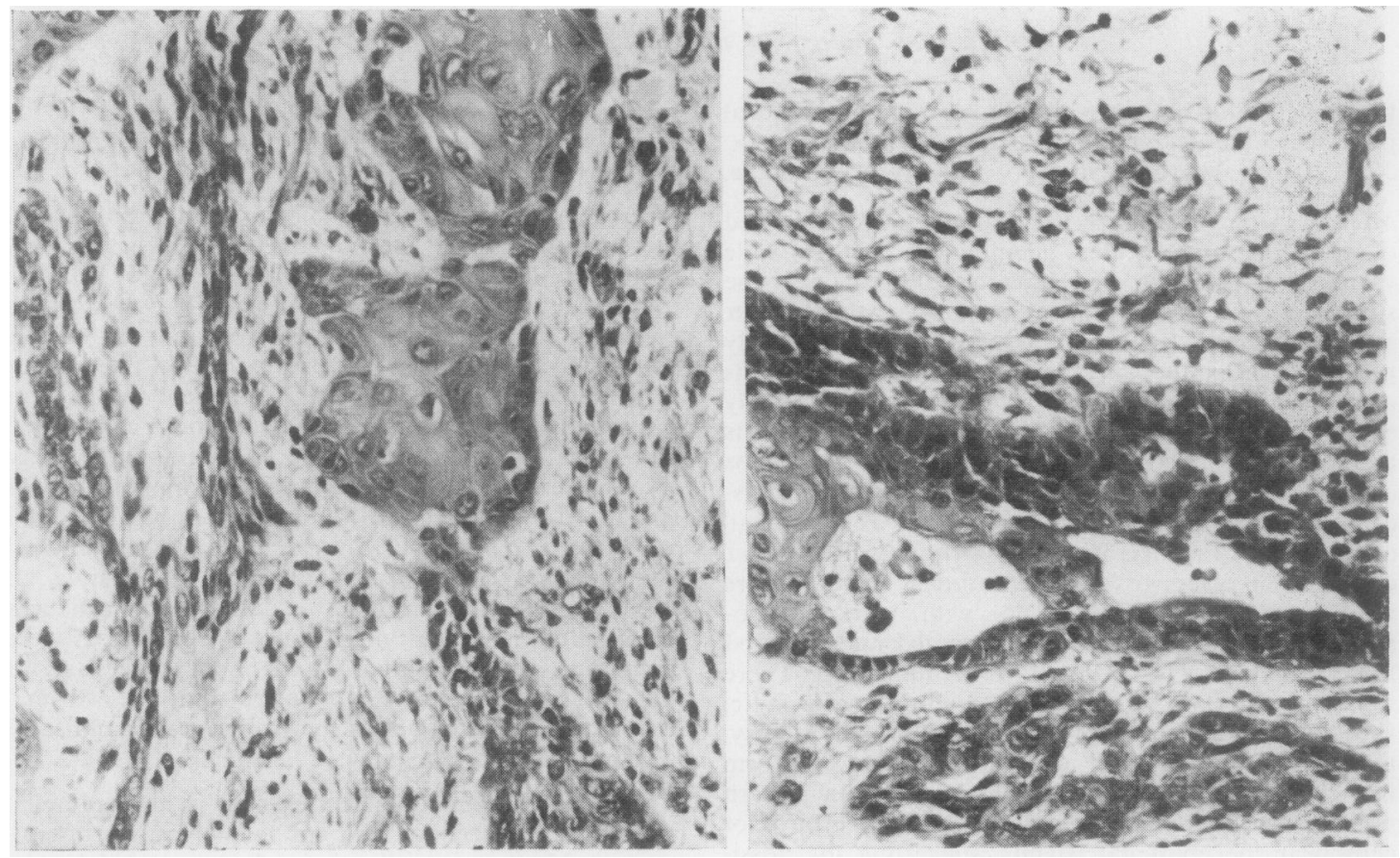

FIG. 8. (Left) Obvious epidermoid areas with oval and spindle-cell stroma, with an area which suggests merging of the epithelium into the stroma. $H$. and $E . \times 75$. (Right) The epithelial component shows epidermoid carcinoma merging into cuboidal epithelium producing tubular appearances. H. and $E . \times 75$.

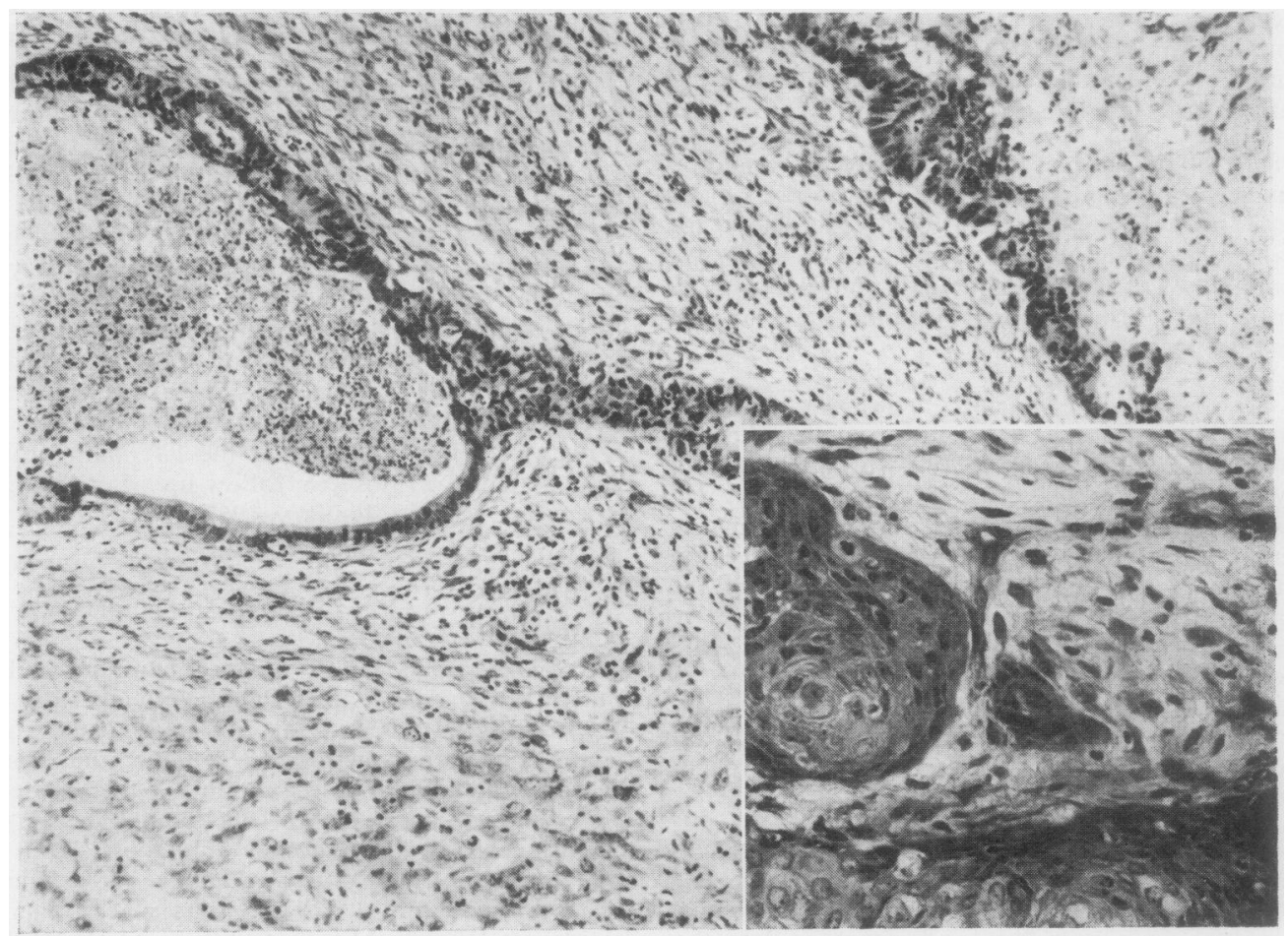

FIG. 9. Marked variability of epithelial component and more cellular pleomorphic area of connective tissue component of tumour. H. and E. $\times 55$. (Inset) Epidermoid areas with some keratinization. H. and E. $\times 70$. 
and containing reticulin and collagen fibrils, was in some places more cellular and pleomorphic (Fig. 9). In yet other places there was marked hyalinization. Only in one area near the surface was a less cellular, oedematous, 'embryonic' type of stroma noted.

Comment The predominance of pleomorphic spindle cells with epithelial malignancy suggests a carcinosarcoma. The 'embryonic' stromal area and the considerable variability of the epithelial component recalls features shared in common with cases 3 and 4 (blastomas).

CASE 8 I.B., a 49-year-old woman and a known case of dextrocardia, presented with a non-resolving pneumonia in February 1968. Chest radiographs suggested a peripheral neoplasm in the left lower lobe with enlargement of the hilar lymph nodes. At operation on 10 April 1968 inversion of the lungs was noted. The lower lobe and hilar nodes on the left side were removed. At follow-up in July 1968, she presented with subacute small bowel obstruction with melaena. Radiographic examination revealed recurrence of the pulmonary neoplasm and a filling defect in the third part of the duodenum and complete situs inversus. At laparotomy on 18 August 1968 a firm nodular, oval

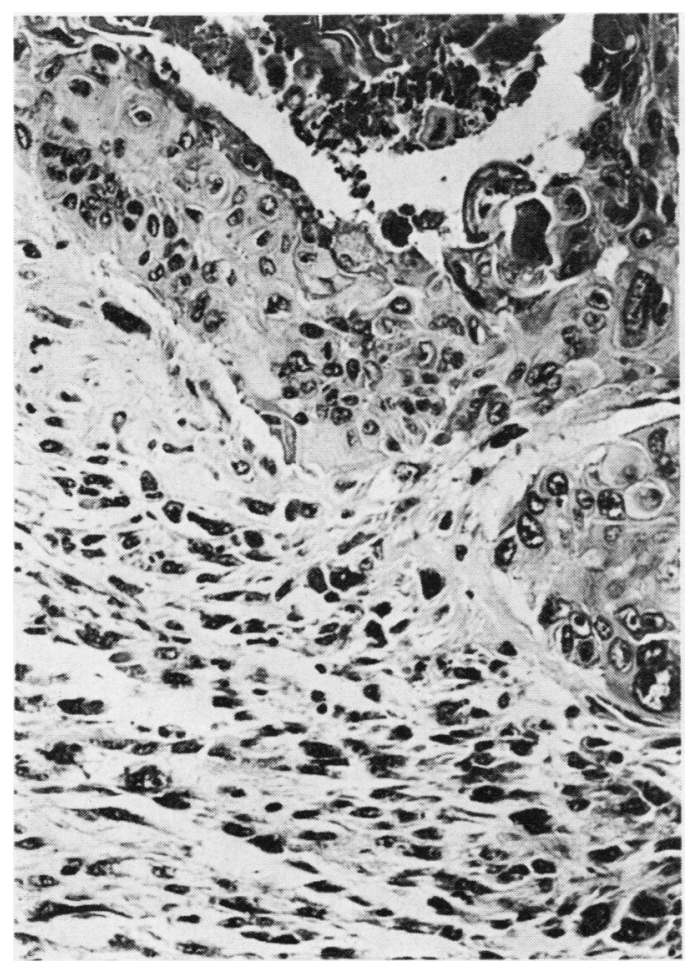

FIG. 10. Lung tumour. Areas of well-differentiated squamous-cell carcinoma together with spindle-shaped and pleomorphic parts of tumour. H. and E. $\times 60$.

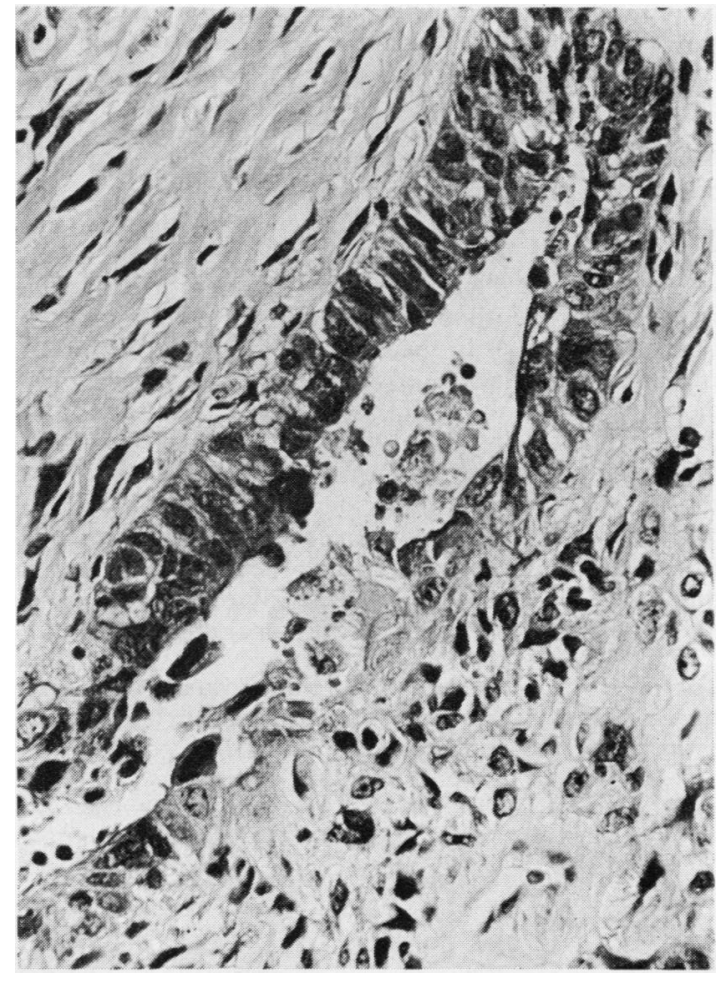

FIG. 11. Lung tumour. Tubular epithelial lined structures surrounded by the less cellular spindle-cell and pleomorphic. sarcomatous component of tumour. $H$. and $E . \times 65$.

tumour, $70 \times 50 \times 35 \mathrm{~mm}$, was removed from the first part of the duodenum. Seven months after resection of the lung tumour the patient died with widespread metastases.

Surgical specimen 1. Left lower lobectomy specimen The macroscopic appearances were those of a firm peripheral basal greyish-white tumour, measuring $\mathbf{8 0}$ $\times 65 \times 60 \mathrm{~mm}$, with involvement of the lower lobe bronchus.

Microscopic appearances A mixed malignancy involving epithelial and connective tissue elements. The epithelial element was mainly epidermoid with pearl formation (Fig. 10), but also present were tubular structures lined by hyperchromatic columnar cells (Fig. 11). The 'stromal' component resembled a fibrosarcoma with an intimate reticulin pattern. In places there was much mature collagen. Mitoses were plentiful.

Surgical specimen 2. Duodenal tumour On microscopic examination this was an ulcerated tumour composed of spindle-shaped and bizarre pleomorphic cells with numerous multinucleated tumour giant cells. Mitoses were frequent. The features were those of a 
pleomorphic sarcoma (Fig. 12-left). The lung tumour was therefore considered a carcinosarcoma, the sarcomatous component of which had resulted in a duodenal tumour metastasis.

Necropsy This showed total situs inversus and local pulmonary tumour with extensive recurrence and metastases to contralateral lower lobe, thyroid, and both kidneys. On microscopical examination the sections of the local pulmonary tumour recurrence were similar to those of the primary tumour. The tumour metastases in the opposite lung, in the thyroid, and in both kidneys showed the features of a pleomorphic sarcoma with scattered multinucleated tumour giant cells. In addition, foci of osseous tissue intimately associated with pleomorphic spindle-shaped cells were present in all the metastases (Fig. 12-right). No cross striations were seen in elongated giant cells. Evidence of the epithelial component of the primary tumour could not be detected in any of the metastases although numerous sections were examined.

Comment This tumour has the features of a carcinosarcoma, the sarcomatous component accounting entirely for the metastatic dissemination.

CASE 9 W.S., a tarmac worker and heavy cigarette smoker aged 66 years, was admitted on 9 November
1966 with a history of increasing shortness of breath for one year. Chest radiographs showed pneumonic changes in the right upper and middle lobes. He improved on treatment with ampicillin. An episode of thromboembolic disease was followed by total collapse of the right lung. Biopsy of a mass in the right main bronchus was reported as 'largely connective tissue with a few large hyperchromatic cells: presumably not characteristic of the whole'. A right pneumonectomy was performed on 14 February 1967. He died suddenly nine months after resection and no necropsy was performed.

Surgical specimen The macroscopic appearances were those of a polypoid tumour arising at the origin of the segmental bronchi of the upper lobe and growing proximally along the bronchus to produce a pedunculated sausage-shaped mass, $30 \times 20 \mathrm{~mm}$, distending the right main bronchus. The lung showed obstructive pneumonitis and gross mucus retention.

Microscopic appearances A mixed tumour consisting of epidermoid epithelial, and pleomorphic spindle-cell sarcomatous components. The epithelial element of the tumour was entirely epidermoid in character with large keratinized central areas surrounded by pricklecell areas with prominent intercellular bridges. Within the latter, there were occasional small groups and
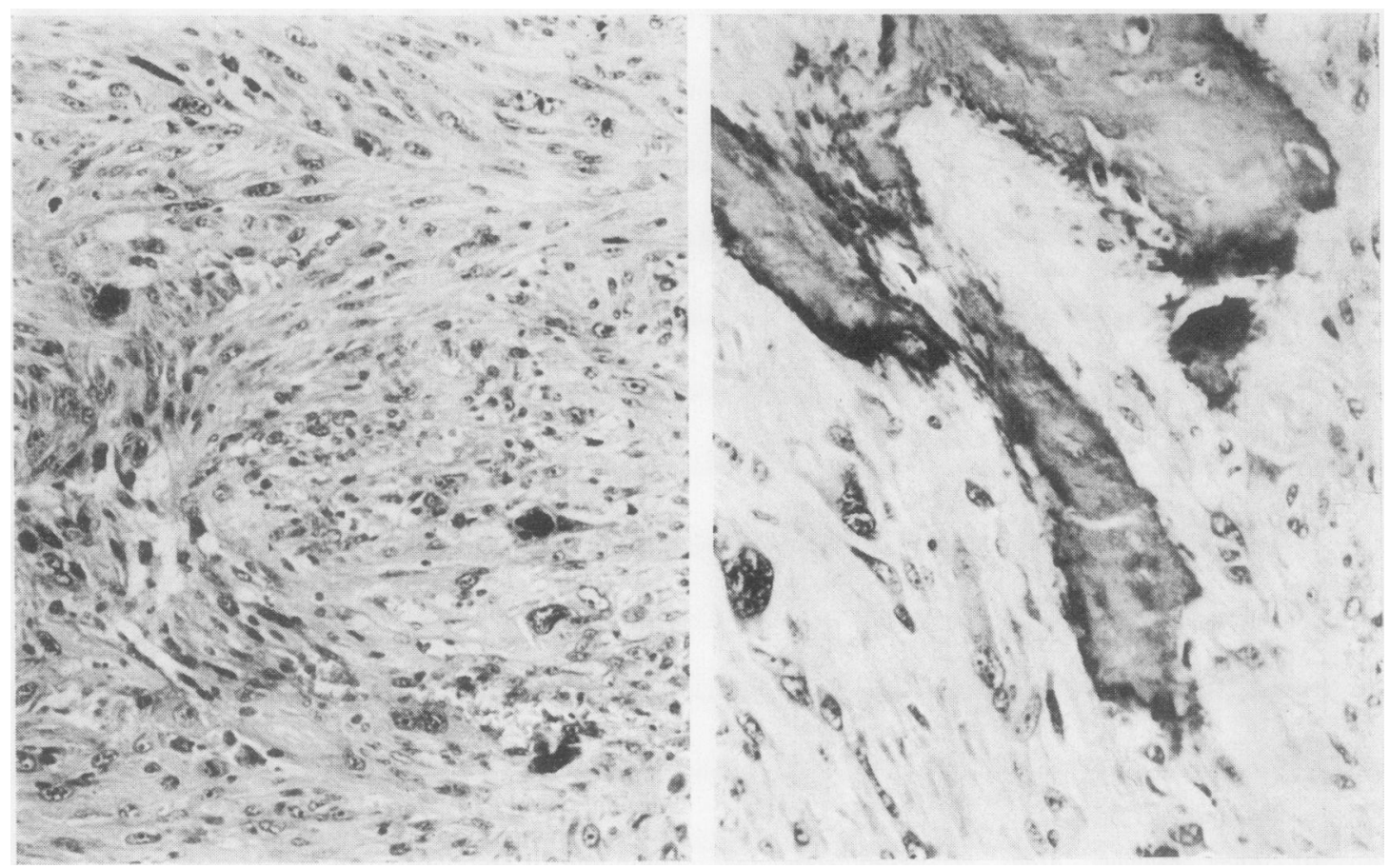

FIG. 12. (Left) Duodenal metastasis. Spindle-cell and pleomorphic sarcomatous appearances. H. and E. $\times 70$. (Right) Osteogenic activity in sarcomatous metastasis in thyroid. $H$. and $E . \times 70$. 

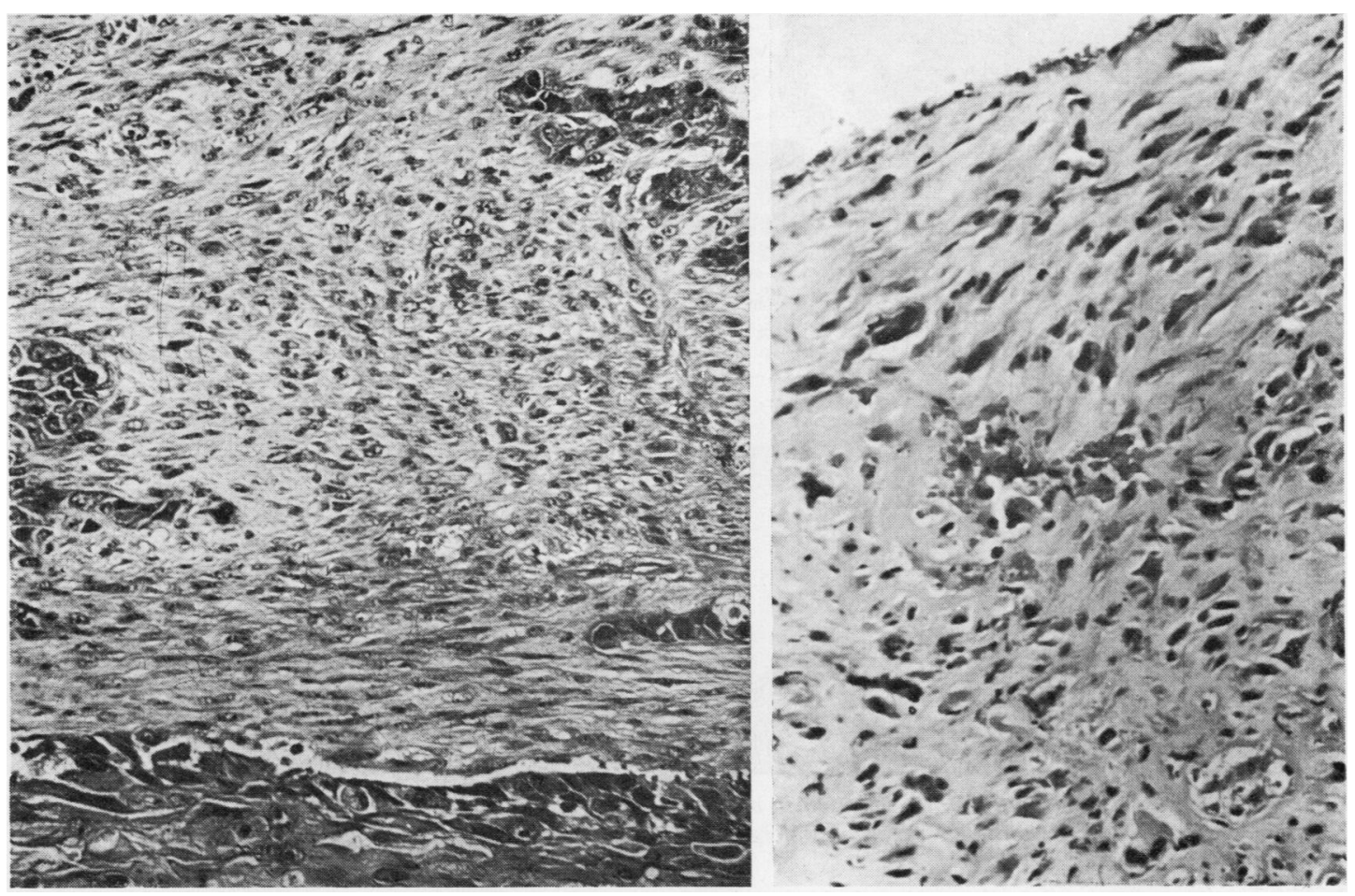

FIG. 13. (Left) A typical field showing large and small islands of epidermoid carcinoma in an apparently pleomorphic sarcomatous stroma. H. and E. $\times 65$. (Right) Bronchial biopsy obtained from surface of polypoid mass showing spindlecell and collagenous tumour. $H$. and $E . \times 75$.

some single keratinized epidermoid carcinomatous cells (Fig. 13-left). Moderate numbers of mitotic figures were present. The surface of the polypoid portion of the tumour, from which the biopsy had been taken, was spindle-celled and collagenous (Fig. 13-right). The adjacent upper lobe bronchus, however, showed epidermoid carcinoma infiltrating the mucous glands and carcinomatous permeation of perivascular and perineural spaces. Epidermoid carcinomatous deposits were found in hilar lymph nodes. In the 'stromal' component the reticulin stain revealed a fine reticulin network surrounding individual cells in the spindle-cell areas, but in close proximity there was a coarser reticulin pattern enclosing several larger cells.

Comment This tumour is regarded as a carcinosarcoma. No embryonic stroma was seen and the epithelial elements were entirely epidermoid without any variation of tendency to tubule formation.

CASE 10 M.C., a 76-year-old man, was a cigarette smoker. He was admitted on 18 November 1970 with a history of haemoptysis eight weeks previously. There was gross clubbing of the fingers and toes. Chest radiographs revealed an opacity in the apical segment of the left lower lobe. Bronchoscopy and bronchography showed no bronchial involvement. A left lower lobectomy was performed on 15 December 1970. At follow-up 18 months later the patient remained well with no clinical or radiographic evidence of recurrence.

Surgical specimen Macroscopic examination showed a peripheral tumour, $40 \mathrm{~mm}$ in diameter, necrotic in the centre, involving the apical segment and overlying the pleura.

Microscopic appearances The tumour showed mixed carcinoma and sarcoma-like appearances, with the epithelium maximal at the periphery and the connective tissue element centrally. The epithelial element was mainly large-cell undifferentiated, but other areas with tubule formation were present (Fig. 14-left). The 'stromal' component was variable; numerous bizarre cells were present, including giant, spindle, and some 'tadpole' forms. In several areas the stroma and epithelium were intermingled and appeared to merge (Fig. 14-right). A feature of the microscopic appearances was the infiltration of stroma by inflammatory cells with 'corpora amylacea', there being an adjacent pneumonitis. 

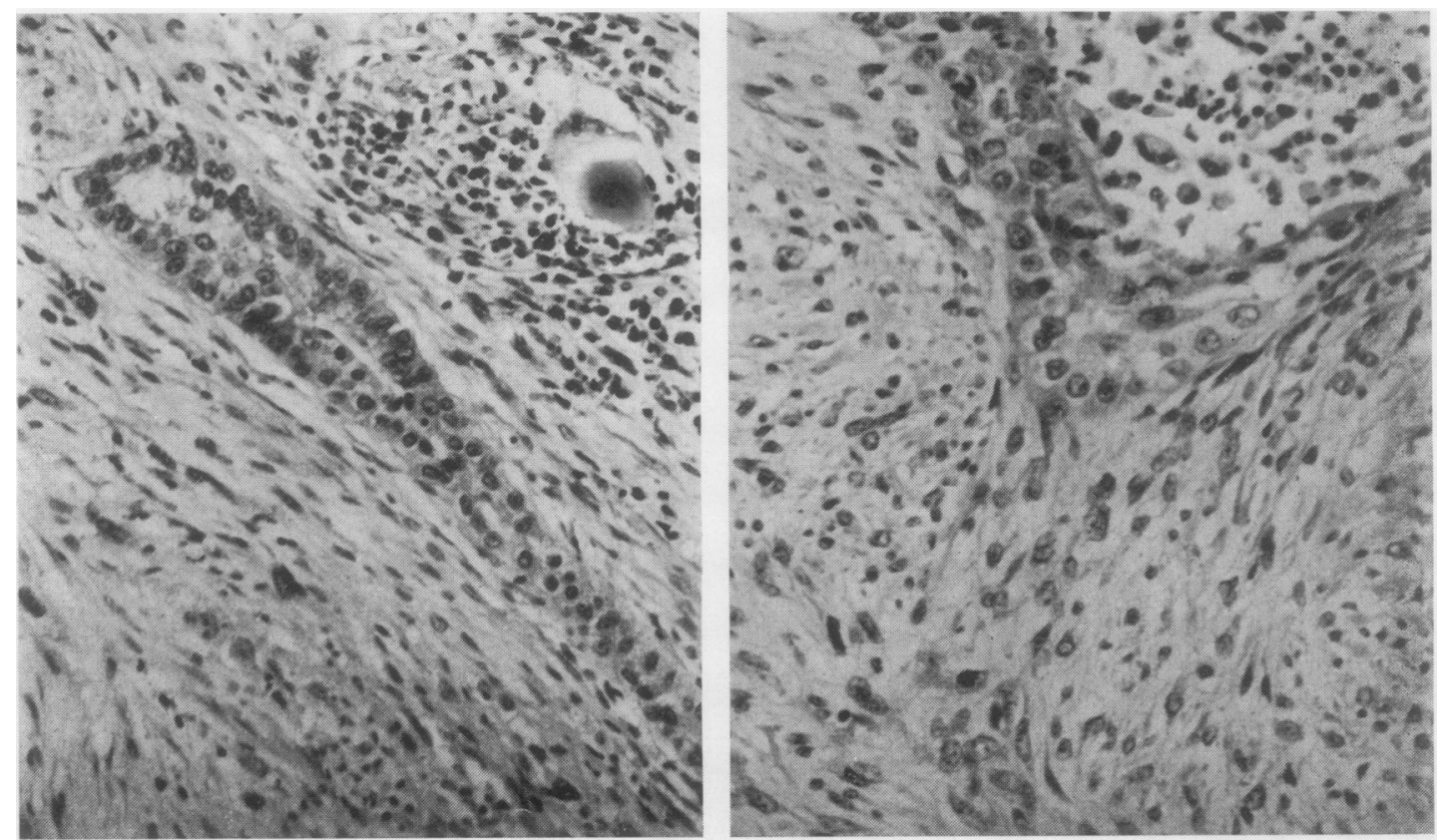

FIG. 14 (Left) An area showing tubule formation in a pleomorphic stroma with a spherule and associated inflammation. $H$. and $E . \times 70$. (Right) A characteristic area of merging of stromal and epithelial cell types. $H$. and $E . \times 70$.

Comment The differential diagnosis of this tumour rests between a carcinosarcoma and an undifferentiated carcinoma with individual spindle-cell spread into the stroma. Separation of the stroma and epithelial elements is quite difficult in parts of the tumour, and in this respect it is dissimilar from the other tumours considered. It is also dissimilar in that it is situated within the parenchyma of the lung, whereas the other carcinosarcomas had an intrabronchial element.

\section{DISCUSSION}

CLINICAL FEATURES Interest is provided by our first patient in view of the rarity of the neoplasm which was indistinguishable from a mixed salivary neoplasm. If the symptoms of obstructive pneumonitis are correlated with the clinical history, it seems possible that this tumour had been present for as long as four years before admission to hospital, suggesting a relatively benign behaviour of the neoplasm. This might be expected in view of the behaviour of this type of tumour in other sites. Lennox (1960) remarks on the total absence of tumours of the mixed salivary variety in the larynx, trachea, and bronchi.

The second patient was found to have a 'chondromatous hamartoma' as an incidental find. ing at necropsy. These asymptomatic tumours usually present as round peripheral opacities on radiographic examination. The remaining cases are discussed collectively, being compared to carcinoma of the bronchus in general.

Age and sex Of the eight patients, six were men: on admission to hospital the mean age was $59 \cdot 1$ (range 40-76) years. Figures for malignant neoplasms of the lungs and bronchi (carcinomas constituting the overwhelming proportion) show a maximum mortality in the seventh decade (range $<4->85$ years) and a sex ratio of 5 males: 1 female (Registrar General, 1971).

History All patients had symptoms referable to the respiratory tract, and three suffered haemo- 은 ptysis. The duration of symptoms varied from one $D$ year to three weeks. Six patients gave a history of cigarette smoking.

Radiography Chest radiographs were considered $\tilde{D}$ indicative of neoplasm in four cases; in the other $\mathrm{N}^{N}$ four cases the nature of the atelectasis suggested a main bronchial occlusion.

Bronchoscopy This was performed in seven $\stackrel{\oplus}{?}$ patients, and in five of them the tumour was seen 0 and biopsy material was obtained. In four patients $\bar{O}$ (cases $3,5,6,9)$ the histology report was made with some reservation. The individual histopatho- $\mathbb{D}$ logical features are listed in the Table. 


\begin{tabular}{|c|c|c|c|c|c|c|c|c|c|c|}
\hline 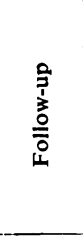 & 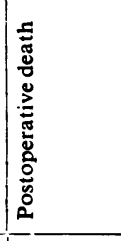 & 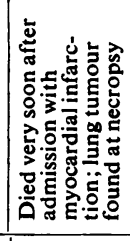 & 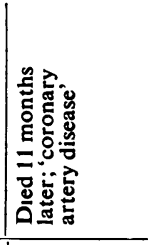 & 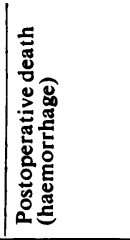 & 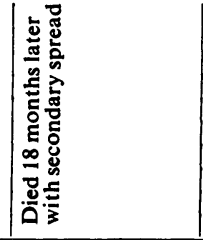 & 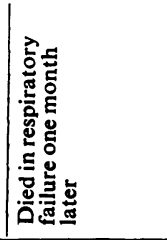 & 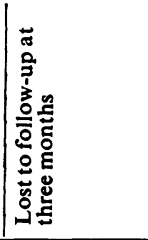 & 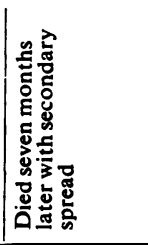 & 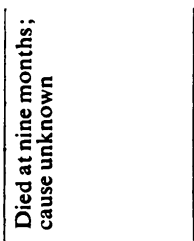 & 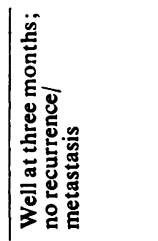 \\
\hline 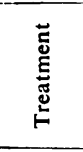 & 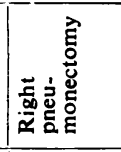 & $\overline{\bar{z}}$ & 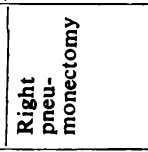 & 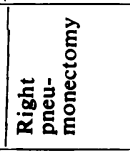 & 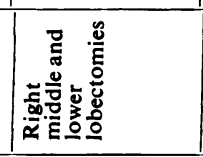 & 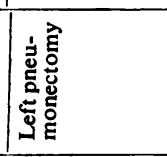 & 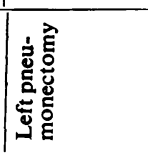 & 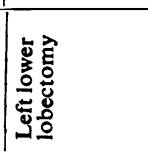 & 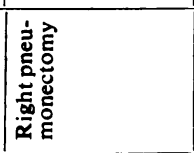 & 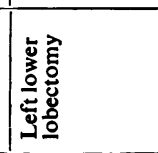 \\
\hline 亳 & 总 & 总 & $\frac{\text { go }}{z}$ & $\mid \frac{\mathscr{0}}{\mathrm{s}}$ & 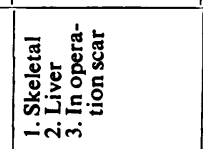 & 总 & |⿺辶⿳亠二口犬 & 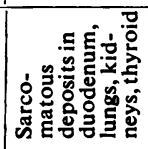 & 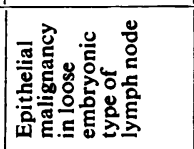 & 产 \\
\hline | & 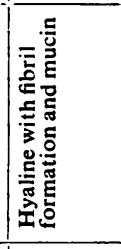 & 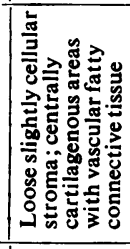 & 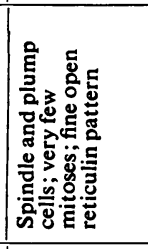 & 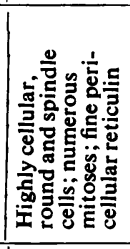 & 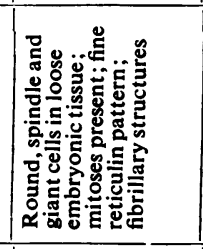 & 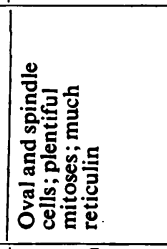 & 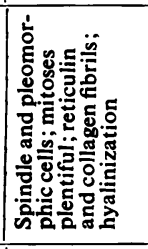 & 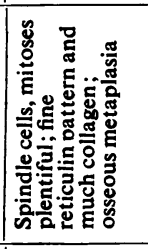 & 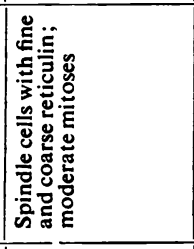 & 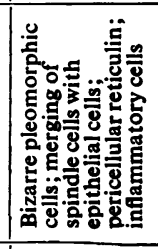 \\
\hline 厗 & 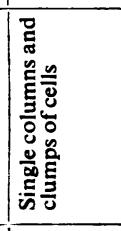 & 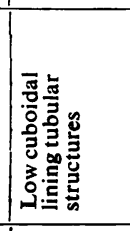 & 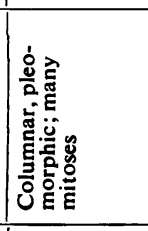 & 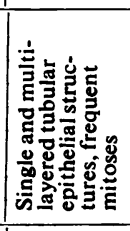 & 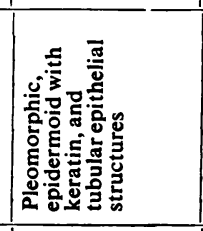 & 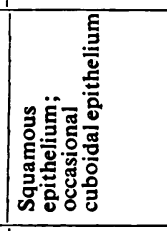 & 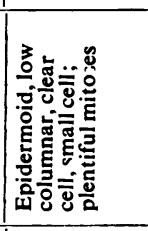 & 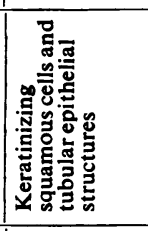 & 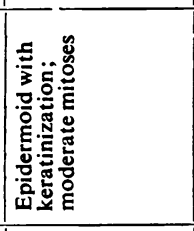 & 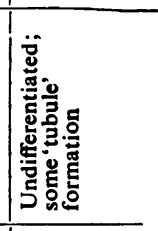 \\
\hline 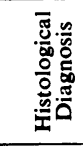 & 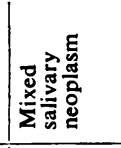 & 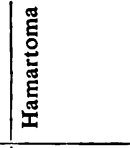 & 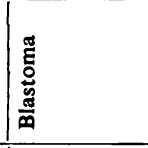 & 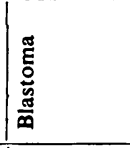 & 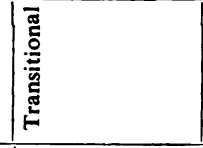 & 龅 & 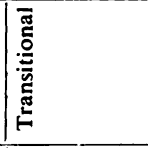 & 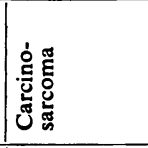 & 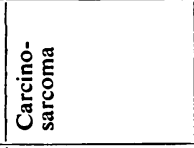 & 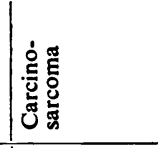 \\
\hline 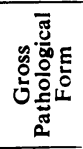 & 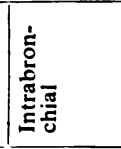 & 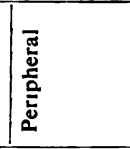 & 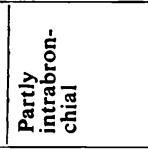 & 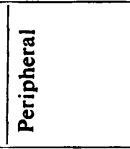 & 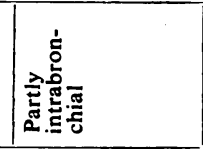 & 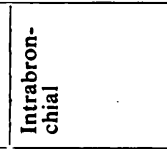 & 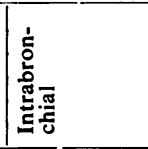 & 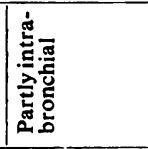 & 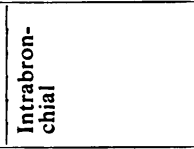 & 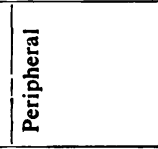 \\
\hline 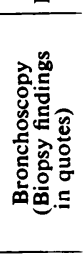 & 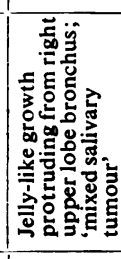 & 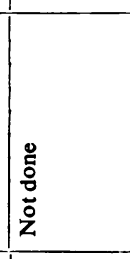 & 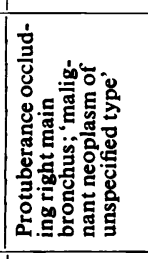 & 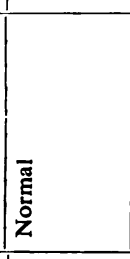 & 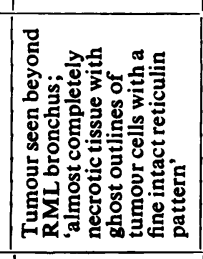 & 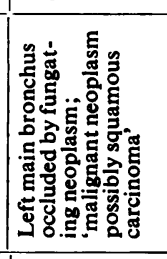 & 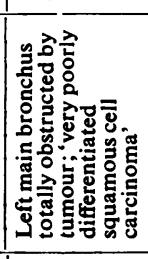 & 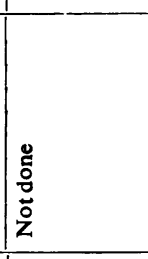 & 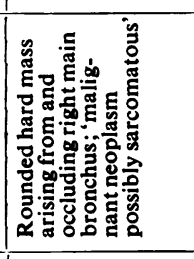 & 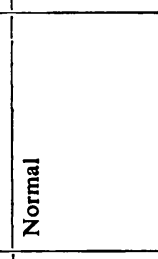 \\
\hline 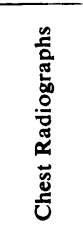 & 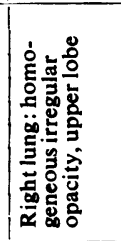 & 总 & 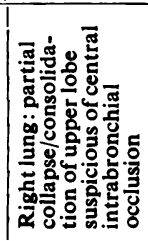 & 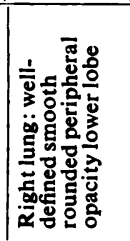 & 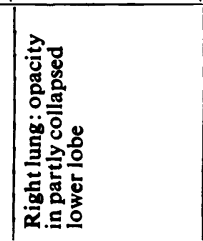 & 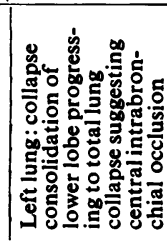 & 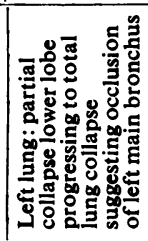 & 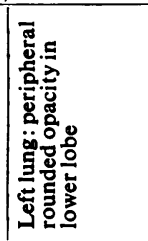 & 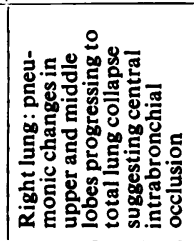 & 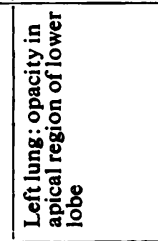 \\
\hline 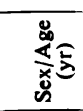 & 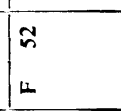 & 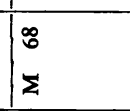 & $\mid \begin{array}{l}\infty \\
\Sigma \\
\Sigma\end{array}$ & $\begin{array}{l}q \\
z\end{array}$ & $\mid \begin{array}{l}\infty \\
n \\
\Sigma\end{array}$ & $\mid \begin{array}{l}\ddot{B} \\
\Sigma\end{array}$ & $\mid \begin{array}{l}\overrightarrow{0} \\
1\end{array}$ & F & $\mid \begin{array}{l}: \\
\Sigma\end{array}$ & $\begin{array}{l}2 \\
\Sigma\end{array}$ \\
\hline 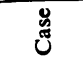 & & | & im & $1+$ & in & 10 & r & $1 \infty$ & la & 10 \\
\hline
\end{tabular}


Operative findings and procedure All patients were considered operable on clinical and radiographic grounds. The gross findings at operation, with the exception of case 7 , were consistent with malignant growth. All operative procedures were intended to be curative, except in case 8 , in whom respiratory function allowed lobectomy only.

Follow-up (Table) One patient remains free from clinical recurrence 18 months after leaving hospital and one patient was lost to follow-up, being free from recurrence when seen three months after discharge. Two patients died from complications of surgical treatment. Three patients who underwent 'curative' surgery died at 9,11 , and 18 months, but only one of these (case 5) had certain evidence of secondary spread at the time of death. Another patient (case 8) died with local recurrence and widespread metastases at seven months. Thus, among the four patients who died following discharge from hospital, the average survival time was $11 \cdot 3$ months.

Metastasis Three patients developed metastases. In each instance the primary tumour contained epithelium which was epidermoid. Distant metastases occurred in two of these (cases 5 and 8), and where histological proof was possible these metastases were all sarcomatous in nature. In the third patient, a local lymph node showed epithelial malignancy (case 9).

Metastasis in cases of pulmonary blastoma is well documented, and the sites quoted include regional nodes, lungs, brain, abdominal viscera, retroperitoneal tissues, and blood vessels. It seems rare for the epithelial component to metastasize alone: metastases described as pure sarcoma have been recorded infrequently (Spencer, 1961; Henry and Keal, 1966; Stackhouse et al., 1969); the most common pattern of metastasis is one which includes both malignant epithelial and connective tissue components (Parker, Payne, and Woolner, 1966; Spencer, 1961; Peabody, 1959; Barson et al., 1968; Stackhouse et al., 1969). The last authors, in stating that both components are usually demonstrable in the metastatic lesion, observe that sarcoma predominates.

Metastasis has been well recognized in cases which have been accepted as pulmonary carcinosarcoma, the sites quoted being regional lymph nodes, lung, skeleton, adrenals, kidneys and other abdominal viscera, brain, and heart. A precise histological definition of the composition of these metastases is often lacking and only one author (Saltykow, 1914) describes separate deposits containing carcinomatous, sarcomatous, and carcino- sarcomatous tissue. Sarcomatous deposits alone have been described by Weber (1939); carcinoma and sarcoma may occur separately in the same patient (Motlik and Triska, 1968). Deposits containing a mixture of carcinoma and sarcoma have been described by Frank (1915) and Kakos, Williams, Assor, and Vasko (1971). The most common form of metastasis is one which contains carcinoma alone (Selye, 1928; Fischer, 1938; Motlik and Triska, 1968; Razzuk et al., 1971).

From the foregoing account it will be seen that the distribution of metastases in both pulmonary blastoma and carcinosarcoma resembles the pattern of distribution which has been described for carcinoma of the lung (Hinson, 1958).

Prognosis Survival of patients with pulmonary blastoma is variable. Bauermeister, Jennings, Beland, and Judson (1966) described a patient who had radiological evidence of neoplasm for 24 years before surgical treatment.

Spencer (1961) quotes the patient described by Barnard (1952) as being alive 15 years after surgical treatment. But short periods of survival following diagnosis or treatment are recorded, e.g., six weeks (Spencer, 1961), nine months (Barson et al., 1968), and six and seven months (Stackhouse et al., 1969) with deaths attributable to metastases.

With regard to endobronchial carcinosarcoma, some authors (Taylor and Rae, 1952; Drury and Stirland, 1959) suggest that this is a relatively favourable lesion. However, Bergmann et al. (1951), in commenting on the six-year postoperative survival of one of their patients, point out the possibility of recurrence. Reference to more recent literature (Stackhouse et al., 1969) indicates lesser survival times for this type of tumour. Razzuk et al. (1971) report a patient who had metastases six months after pneumonectomy and who died 21 months after operation for an endobronchial pedunculated carcinosarcoma. Many cases of carcinosarcoma show a gross pattern of polypoid intrabronchial extension associated with parenchymal tumour involvement, and survival periods following treatment of less than one year are not uncommon.

Goldman (1965) showed that for carcinoma of the lung survival rates were more closely associated with the histological type of tumour and its degree of differentiation than with the method of treatment used.

Our series of patients is too small to allow us to draw any useful conclusions concerning the prognosis of these mixed primary malignant tumours of the lungs, but whether they occur in 
a peripheral or an intrabronchial situation, we feel that caution is justified with regard to prognosis after treatment.

\section{HISTOPATHOLOGY}

Benign mixed tumours of the 10 cases presented, only cases 1 and 2 are considered benign in terms of their histopathological appearances. Case 1 is a classical example of a pleomorphic adenoma (mixed salivary tumour) growing within a bronchus. This tumour complies with WHO group IX, mixed tumours, which includes tumours resembling mixed salivary neoplasms. However, the colour photomicrographs illustrating this group, namely Figs 31 and 32, could be interpreted as examples of the common 'chondromatous hamartoma'. Histopathologists would not confuse a pleomorphic adenoma with a chondromatous hamartoma. Pleomorphic adenomas, common neoplasms of salivary glands but very rare in the bronchus, are well-defined entities whose cell of origin. at least in salivary glands, is well established (Eneroth, 1964). This cell is the myoepithelial cell, a specialized specific cell found in limited sites but capable of differentiation along epithelial and mesodermal lines.

The much more common chondromatous hamartomas are composed of tubular structures lined by low cuboidal epithelium in association with connective tissue elements such as cartilage, and these are clearly mixed tumours in that there is proliferation of epithelium and mesenchymal tissue. In view of this combination of fairly mature components of lung, the term hamartoma has been widely accepted. Willis (1962), however, does not regard such tumours as true hamartomas but suggests that they are analogous to fibroadenomas of the breast. Our example of such a common tumour (case 2) is chosen for two reasons: (1) in one area the stroma contains numerous stellate cells resembling the embryonic tissue and cuboidal epithelial-lined tubules seen in some examples of pulmonary blastoma; (2) because such areas also fulfil the criteria laid down by Spencer (1968) for his second variety of non-cartilagenous local pulmonary hamartoma. Local pulmonary hamartomas, we feel, should find a place in any revised classification of lung tumours and be designated benign. The term 'benign mixed tumour of bronchus', preferred by Willis (1962), could easily lead to confusion with the distinctive group of mixed salivary tumours (pleomorphic adenomas) and also it might suggest an intrabronchial tumour, whereas of course they are characteristically peripheral. This benign group of mixed tumours, therefore, includes pleomorphic adenomas and local pulmonary hamartomas, both cartilagenous and non-cartilagenous. The latter would appear to correspond closely to benign pulmonary blastomas.

We suggest that in a revision of the WHO classification, type $\mathrm{IX}_{1}$ 'mixed tumours' should be subdivided into $1 \mathrm{a}$ pleomorphic adenomas; 1b local pulmonary hamartomas (cartilagenous); and 1c local pulmonary hamartomas (non-cartilagenous), including histopathologically benign pulmonary blastomas. A tumour such as that of case 2, with some embryonic stroma and large cartilagenous areas, would be included under $1 \mathrm{~b}$.

Malignant mixed tumours A review of the published cases of pulmonary blastomas (Spencer, 1961; Souza et al., 1965; Bauermeister et al., 1966; Barson et al., 1968; Stackhouse et al., 1969) reveals that cytological evidence of malignancy is present in either the epithelial or the stromal component, or often in both. Carcinosarcomas reported in the literature, as implied by their name, involve cytological malignancy in both epithelial and stromal components. The WHO classification of mixed tumours IX includes 'carcinosarcomas of embryonal type' (pulmonary blastomas), in which the distinctive criteria are the presence of stroma resembling embryonic mesenchyme and irregular acinar tissue, or squamous epithelium. The need for histopathological evidence of malignancy is not stressed, presumably because this is difficult to define and is somewhat subjective.

Also included with WHO IX ${ }_{3}$ are 'other carcinosarcomas', the main distinctive feature being the presence of 'areas characteristic of soft tissue sarcoma'. A wide range of well-differentiated epithelial malignancy is included within this group. Variability of the carcinomatous component, differentiated or undifferentiated, is not mentioned.

The tumours which we have presented from cases 3 to 10 inclusive are histologically malignant: in case 3 the epithelial elements alone showed malignancy but in the remainder, cases 4 to 10, pleomorphism and increased mitotic activity are present in both the epithelial and the connective tissue components. Cases 3 and 4 fulfil the WHO criteria for carcinosarcoma of embryonal type and closely resemble the majority of published examples of pulmonary blastoma. We consider cases 8,9 , and 10 to correspond to

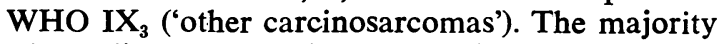
of published examples of carcinosarcoma consist of epidermoid carcinomatous islands in a spindle-cell sarcomatous 'stroma', as seen in these three cases. Cases 5, 6, and 7, however, have 
features of both subgroups containing areas resembling embryonal mesenchyme. Another feature common to the neoplasms in these latter three cases is the marked variability of the epithelial component within each tumour. Therefore we have termed them 'transitional'.

Collectively, cases 3 to 10 inclusive show a spectrum from blastomas characterized by tubular epithelial structures, sometimes with keratinized areas in an embryonic stroma, to mixed malig. nancy with acinar and epidermoid epithelial malignant components in a spindle-cell sarcomatous background, as in so-called carcinosarcomas. We suggest that revision of the international tumour classification should take account of and include 'transitional' forms. Further, we suggest that the carcinosarcomas of embryonal type should be designated pulmonary blastomas, and that although it is appreciated that it may be difficult to define histopathological malignancy in the zone between local pulmonary hamartoma and some pulmonary blastomas, only tumours with malignant features in one or both components should be included.

In any revision of the classification of mixed tumours provision should also be made for the rare occurrence of malignant variants of 'chondromatous hamartoma' (Simon and Ballon, 1947; Cavin, Masters, and Moody, 1958).

The problem of apparent merging of epithelial and connective tissue elements Illustrations of pulmonary blastomas described in various papers appear to be very similar but the authors do not come to the same conclusions concerning the separation or merging of the two components. Spencer (1961), in reporting four cases, concludes that merging is a feature. This view is shared by Henry and Keal (1966) in their case report. On the other hand, Stackhouse et al. (1969) stress the absence of merging of the two components in their four cases of pulmonary blastoma. Our case material supports the latter view (cf. cases 3 and 4), but we noted some evidence of merging in cases 5 and 6 ('transitional'). The carcinosarcomas (cases 8,9 , and 10) show the presence of streaming and merging of the epithelial and stromal components. It is difficult to assess the significance of small clumps of malignant cells in the stroma of these malignant mixed tumours. The possibility that these cells are epithelial in origin and account solely for the cytological malignancy seen in the stroma questions the validity of regarding carcinosarcoma as a true entity. This is a point which has been made by Saphir and Vass (1938) and Willis (1967). They have stressed that many examples of carcinosarcomas represent a 'pseudo-mixed' pic- $\frac{0}{\sigma}$ ture, an entity well accepted in some sites like the $\bar{O}$ larynx and the oesophagus. While we agree with $\frac{\bar{m}}{\frac{\bar{T}}{7}}$ Saphir and Vass, and Willis and others that many $\mathbb{\varnothing}$ examples in the old literature with areas composed of spindle-cell variants may have been mis- ${ }^{-\infty}$ interpreted as carcinosarcomas and that it is most $\vec{\circ}$ important to be aware of such a fallacy, we con- $\overrightarrow{\vec{\omega}}$ clude that the frequent differentiation into muscle, $\stackrel{\omega}{\stackrel{\omega}{ }}$ cartilage, and bone considered in more detail $\vec{x}$ below leaves no doubt that carcinosarcoma is a true entity with simultaneous malignancy of epi-. thelium and connective tissue. Careful review of our own material leaves us in some doubt only जु concerning case 10 . Several opinions were soughto on this tumour and the majority favoured a diagnosis of carcinosarcoma.

Differentiation of connective tissue component $\Phi$ Drury and Stirland (1959) reported a carcino-흥 sarcoma of the lung containing areas of new $\mathbb{D}$ bone formation in the spindle-cell areas, while the $\overrightarrow{0}$ epithelial component was epidermoid, a combina-N tion of appearances similar to that in our case 8 , except that in the latter bone formation by the sarcomatous component was seen only in the mediastinal recurrence and in metastases. They considered the production of reticulin, collagen, $\frac{\varnothing}{\varnothing}$ and bone as strong evidence that the spindle-celled $\cong$ areas were not epithelial variants. Similarly, Privé, $\overrightarrow{\overrightarrow{0}}$ Tellem, Meranze, and Chodoff (1961) regarded chondrosarcomatous areas in their case report of a central carcinosarcoma as evidence in favour of carcinosarcoma being regarded as a true entity. Henry and Keal (1966) presented an example of 응 pulmonary blastoma with striated muscle in $x$ several areas. We did not encounter any differ- $\frac{0}{3}$ entiation of the connective tissue component into mature elements such as muscle or bone in either of our two pulmonary blastomas.

Histogenesis Many authors have suggested that pulmonary blastomas, being peripheral, are을 derived from mesodermal tissue in accordance with Waddell's theory of the development of the lung (Spencer, 1961; Motlik and Triska, 1968). N The latter authors suggest that pulmonary blastomas can be regarded as 'mixed mesodermalo tumours' and suggest that they may have a histo-o genesis in common with peripheral chondromat- $\frac{\mathscr{C}}{\mathbb{D}}$ ous hamartomas. Though our example of chondro- $\stackrel{\infty}{+}$ matous hamartoma was included because of the presence of 'embryonic stroma' at its edge, we consider it unlikely that they have a common origin, because no blastoma with mature cartila- $-\frac{\mathbb{\mathbb { Q }}}{\mathbb{Q}}$ genous areas has been reported and the rare malig- 
nant hamartomas have no resemblance to blastomas. If pulmonary blastomas are in any way related to pulmonary hamartomas they must be related to the non-cartilagenous ('peripheral') local pulmonary hamartoma, as suggested by Spencer (1968).

Motlik and Triska (1968) considered that central carcinosarcomas had a separate histogenesis from pulmonary blastoma, being derived truly from central epithelium (entoderm) with simultaneous malignancy in the epithelium and the connective tissue. Our material, with some malignant tumours showing transitional features and sharing the appearances of 'centrally' and 'peripherally' derived neoplasms, makes a separate histogenesis of the tumours unlikely. In common with Stackhouse et al. (1969) we consider that the histogenesis of the entire group of mixed tumours of the lung remains obscure.

We are grateful to the surgeons at the Llandough, Sully, and Frenchay Hospitals for allowing us to describe patients under their care.

We are indebted to Professor E. D. Williams for his helpful comments in the preparation of this paper and we would like to acknowledge the efforts of $\mathrm{Mr}$. P. Wade, Librarian, Royal Society of Medicine, in obtaining literature from foreign journals. We are indebted to Mr. R. Boothy for the photography.

\section{REFERENCES}

Barnard, W. G. (1952). Embryoma of lung. Thorax, 7, 299.

Barson, A. J., Jones, A. W., and Lodge, K. V. (1968). Pulmonary blastoma. J. clin. Path., 21, 480.

Bauermeister, D. E., Jennings, E. R., Beland, A. H., and Judson, H. A. (1966). Pulmonary blastoma, a form of carcinoma. Amer. J. clin. Path., 46, 322.

Bergmann, M., Ackerman, L. V., and Kemler, R. L. (1951). Carcinosarcoma of the lung. Cancer (Philad.), 4, 919.

Cavin, E., Masters, J. H., and Moody, J. (1958). Hamartoma of the lung. Report of one malignant and three benign cases. J. thorac. cardiovasc. Surg., 35, 816.

Drury, R. A. B., and Stirland, R. M. (1959). Carcinosarcomatous tumours of the respiratory tract. J. Path. Bact., 77, 543.

Eneroth, C. M. (1964). Histological and clinical aspects of parotid tumours. Acta oto-laryng. (Stockh.), Suppl. 191.

Fischer, W. (1938). Zur Kenntnis der Lungenkrebse. Acta Un. int. Cancr., 3, 221.

Frank, A. (1915). Ein Karzinosarkom der Lunge. Schmidts Jb. ges. Med., (Ergänzungsheft), 322, p. 149.

Goldman, K. P. (1965). Histology of lung cancer in relation to prognosis. Thorax, 20, 298.
Henry, K., and Keal, E. E. (1966). Pulmonary blastoma with a striated muscle component. Brit. J. Dis. Chest, 60, 87.

Hinson, K. F. W. (1958). The spread of carcinoma of the lung. In Carcinoma of the Lung, edited by J. R. Bignall, p. 130. Livingstone, Edinburgh and London.

Kakos, G. S., Williams, T. E., Assor, D., and Vasko, J. S. (1971). Pulmonary carcinosarcoma. J. thorac. cardiovasc. Surg., 61, 777.

Kreyberg, L. (1967). International Histological Classification of Tumours: No. 1. Histological Typing of Lung Tumours. WHO, Geneva.

Lennox, B. (1960). The pleomorphic adenomata. In Recent Advances in Pathology, 7th ed., edited by C. V. Harrison, Ch. 1, p. 6. Churchill, London.

Motlik, K., and Triska, J. (1968). Bronchopulmonary carcinosarcomas. Acta Univ. Carol. Med. (Praha.), 14, 3.

Parker, J. C., Payne, W. S., and Woolner, L. B. (1966). Pulmonary blastoma (embryoma). J. thorac. cardiovasc. Surg., 51, 694.

Peabody, C. N. (1959). Carcinosarcoma of lung of peripheral origin. J. thorac. Surg., 37, 766.

Privé, L., Tellem, M., Meranze, D. R., and Chodoff, R. D. (1961). Carcinosarcoma of the lung. Arch. Path.. 72, 351.

Razzuk, M. A., Urschel, H. C., Race, G. J., Arndt, J. H., and Paulson, D. L. (1971). Carcinosarcoma of the lung. J. thorac. cardiovasc. Surg., 61, 541.

Registrar General (1971). Statistical Review of England and Wales for the Year 1969. Part 1. Tables, Medical. H.M.S.O., London.

Saltykow, S. (1914). Beiträge zur Kenntnis des Karzinosarkoms. Verh. dtsch. path. Ges., 17, 351.

Saphir, O., and Vass, A. (1938). Carcinosarcoma. Amer. J. Cancer, 33, 331.

Selye, H. (1928). Über zwei bemerkenswerte Fälle von Karzinosarkom. Med. Klin., 31, 1197.

Simon, M. A., and Ballon, H. C. (1947). An unusual hamartoma (so-called chondroma of lung). J. thorac. Surg., 16, 379.

Souza, R. C., Peasley, E. D., and Takaro, T. (1965). Pulmonary blastomas. A distinctive group of carcinosarcomas of the lung. Ann. thorac. Surg., 1, 259.

Spencer, H. (1961). Pulmonary blastomas. J. Path. Bact., 82, 161 .

(1968). Pathology of the Lung, 2nd ed. Pergamon Press, London.

Stackhouse, E. M., Harrison, E. G., and Ellis, F. H. (1969). Primary mixed malignancies of lung: carcinosarcoma and blastoma. J. thorac. cardiovasc. Surg., 57, 385.

Taylor, H. E., and Rae, M. V. (1952). Endobronchial carcinosarcoma. J. thorac. Surg., 24, 93.

Waddell, W. R. (1949). Organoid differentiation of the fetal lung. Arch. Path., 47, 227.

Weber, F. (1939). Ein Karzinosarkom der Lunge. Zbl. allg. Path. u path. Anat., 72, 113.

Willis, R. A. (1962). The Borderland of Embryology and Pathology, 2nd ed., p. 386. Butterworths, London. (1967). Pathology of Tumours, 4th ed., p. 138. Butterworths, London. 